Jurnal Pengajian Melayu - JOMAS, Jilid 32(1), 2021: 29-48

\title{
SIRI' DALAM ELONG MASYARAKAT BUGIS DI DAERAH TAWAU, SABAH
}

\author{
('SIRI” IN THE ORAL TRADITION OF BUGINESE 'ELONG'
}

IN TAWAU, SABAH)

Mansur Tanra

mansurtanra@gmail.com

\section{Asmiaty Amat Amat}

amat@ums.edu.my

Universiti Malaysia Sabah, Kota Kinabalu

Malaysia

Received: 24 November 2020; Accepted: 8 April 2021

\begin{abstract}
The Bugis people, originally from Sulawesi, has moved to and enhanced multiculturalism in Sabah. They gather in communities that retain many ancestral traditions despite inhabiting faraway lands. They are proud of inheriting their local Buginese wisdom, preserved and well-protected, especially by elders. This wisdom is passed on to subsequent generations to be practised - even in modern times. One such wisdom is called 'siri" which represents pride and dignity upon which they build their lives. Therefore, this paper aimed to identify values reflecting 'siri" in the Buginese 'elong' using Paul Ricoeur's Hermeneutic approach. 'Elong' or words were obtained through interviews conducted on informants aged 50 and above in the Buginese community during a field study at Tawau. Findings showed a few themes within the 'elong', such as making a living, knowing the importance of knowledge, having good manners, preserving dignity and forgiving. The examination of 'elong' proved that they contain 'siri" to steer the Buginese living within various communities.
\end{abstract}

Keywords: Siri', Elong, the Bugis, Paul Ricoeur's Hermeneutics. 


\begin{abstract}
Abstrak
Masyarakat Bugis yang berasal dari Sulawesi telah mewarnai kepelbagaian budaya yang terdapat di Sabah. Masyarakat Bugis hidup dalam komuniti yang masih mengekalkan tradisi nenek moyang mereka meskipun terpisah jauh dari tanah leluhur mereka. Orang Bugis sangat berbangga dengan kearifan lokal yang diwarisi. Kearifan lokal tetap dipertahankan dan dijaga dengan kemas terutama oleh golongan tua. Mereka mewariskan kearifan lokal ini kepada generasi berikutnya supaya tidak luput ditelan oleh arus kemodenan. Siri' adalah antara warisan yang masih dipertahankan kerana merupakan harga diri dan maruah yang menjadi tatanan cara hidup mereka. Kajian ini merungkai nilai siri' yang terkandung dalam elong Bugis dengan menggunakan Pendekatan Hermeneutik Paul Ricoeur. Elong atau kata-kata diperoleh melalui kajian lapangan dengan menemu bual beberapa orang informan Bugis berumur lebih 50 tahun di sekitar daerah Tawau. Dapatan kajian menunjukkan bahawa terdapat beberapa tema yang digambarkan dalam elong Bugis seperti mencari rezeki, kepentingan menuntut ilmu, menjaga budi pekerti, menjaga harga diri, dan memberi kemaafan. Penelitian terhadap elong membuktikan bahawa elong yang diungkapkan orang Bugis memiliki nilai siri'untuk memandu masyarakat Bugis untuk hidup bermasyarakat.
\end{abstract}

Kata Kunci: Siri', Elong, masyarakat Bugis, Hermeneutik Paul Ricoeur, Tawau.

\title{
Pengenalan
}

Masyarakat Bugis yang berada di daerah Tawau pada hari ini ialah generasi anak cucu orang Bugis yang berhijrah dari Sulawesi Selatan, Indonesia sejak abad ke-19. Pada abad ke-19, mereka telah mendominasi aktiviti perdagangan di perairan Sabah terutamanya di bahagian Pantai Timur Sabah (Asmiaty Amat Amat, 2012; Asmiaty Amat et al., 2020). Kemampuan orang Bugis berasimilasi dan beradaptasi dengan masyarakat setempat menjadi salah satu faktor mereka diterima oleh masyarakat tempatan. Meskipun mereka telah hidup dengan beradaptasi dengan masyarakat setempat, mereka masih berpegang teguh dengan adat pangngadereng yang diamalkan oleh nenek moyang mereka di Sulawesi. Menurut Ismail (2013), Pangngadereng merupakan falsafah tertinggi yang mengatur masyarakat dan cara hidup masyarakat Bugis. Pangngadereng mengandungi siri' yang sangat bernilai bagi masyarakat Bugis. Siri' ialah tunjang pangngadereng yang harfiahnya ialah perasaan malu atau harga diri.

\section{Latar Belakang}

Masyarakat Bugis di Sabah masih lagi berpegang teguh dengan konsep siri'. Siri' telah menjadi satu khazanah yang paling sakral dalam masyarakat Bugis. Khazanah ini terkandung dalam sistem adat yang dikenali sebagai pangngadereng. Menurut Asmiaty Amat (2012), khazanah ini perlu diketengahkan untuk pengetahuan umum. Oleh itu, bagi mengetengahkan siri' ke pengetahuan umum, indikator yang akan digunakan ialah elong Bugis. Elong dalam masyarakat Bugis adalah bentuk nyanyian seperti yang dinyatakan oleh Herianah (2011). Menurut Mustafa (2011) dan Abdul (2010) pula, dari sudut kesusasteraan elong ialah sejenis puisi kerana mempunyai persamaan dengan pantun dan syair. Elong mengandungi pappaseng seperti yang telah dinyatakan oleh Iskandar (2016), Johar dan Ambo (2010). Perkara yang sama turut dinyatakan oleh Sikki 
dan Nurwahyuni dalam Andi (2018), yang menemui nilai saling menghormati dan menghargai, keimanan atau keyakinan, adat istiadat, cinta dan keteguhan dalam elong melalui pappaseng dan pappangaja serta manfaatnya dalam masyarakat.

Kewujudan nilai siri' dalam elong Bugis sebagai salah satu bentuk kesusasteraan masih tidak disedari secara meluas dalam masyarakat Bugis itu sendiri khasnya dan masyarakat lain amnya (Asmiaty Amat Amat, 2012). Kajian terhadap siri' dalam elong didapati masih belum dilakukan secara holistik dan konsep elong itu sendiri menimbulkan sedikit kekeliruan. Terdapat kefahaman bahawa elong merupakan lagu kerana lagu dalam bahasa Bugis disebut elong atau kelong. Meskipun terdapat beberapa kajian yang telah dilakukan mengenai elong, terutamanya oleh sarjana dari Sulawesi Selatan ataupun dari luar negara, isu-isu yang dibangkitkan tidak memberikan gambaran secara khusus mengenai siri' yang terdapat dalam elong Bugis dalam pelbagai aspek seperti yang dinyatakan oleh Herianah (2009).

\section{Sorotan Kajian}

Nensilianti dalam Nurfathana (2013) menyatakan bahawa puisi rakyat Bugis yang disebut elong merupakan salah satu karya seni masyarakat Bugis pada zaman dahulu. Elong mengandungi syair dan melodi yang menggambarkan pemikiran, falsafah hidup, watak, pesanan, petua, dan ajaran moral. Kata-kata yang digunakan dalam elong menurut Mustafa (2011) ialah kata-kata pilihan yang bersifat figuratif atau kiasan. Di samping itu, jeda, nada, serta irama penuturnya terdengar jelas sekali kestabilannya. Elong merupakan kekayaan tradisi yang mengandungi nilai luhur yang tidak boleh diabaikan sebagai salah satu warisan budaya.

Uniawati (2013) dalam kajiannya mengungkapkan bahawa elong ialah sejenis karya sastera Bugis yang mengandungi frasa pendek mengenai falsafah kehidupan masyarakat Bugis yang berisi pesan, nasihat, cinta, pujian, kritikan, kebencian dan rindu, cerita, dan lain-lain. Nurul (2018) dan Abdullah (2009) bersetuju bahawa elong bukan sahaja mengandungi ungkapan percintaan, petua, memberi semangat, dan ada yang dikhususkan untuk kanak-kanak pertengahan umur tetapi turut memiliki nilai keagamaan dan nilai siri'na pesse.

Elong terbahagi kepada beberapa bentuk yang disesuaikan dengan kegunaannya. Ada yang digunakan dalam acara perkahwinan atau acara ritual lain ataupun hanya digunakan sebagai hiburan seperti yang telah dijelaskan oleh Syamsurijal (2017). Sudarmin (2014) pula menyatakan bahawa dengan menyingkap makna elong secara tersurat atau tersirat, seseorang dapat mengimplementasi nasihat-nasihat leluhur dalam kehidupan sehari-hari bagi mengelak daripada menyimpang dan menghindari perbuatan jahat, seperti melanggar adat istiadat, bicara, rapang, dan wari yang merupakan 'standart code' masyarakat Bugis.

Mahluddin (2017) pula menyimpulkan bahawa elong merupakan karya sastera berbentuk lisan. Beliau menjelaskan bahawa elong juga disamakan dengan syair yang dinyanyikan dan ia berisi petua dan nasihat. Hal ini kerana, ada waktu tertentu elong dilagukan dengan diiringi petikan kecapi ataupun gambus Bugis yang didendangkan dalam acara-acara tertentu seperti dalam majlis perkahwinan dan sebagainya. Dalam kajian yang dijalankan oleh Herianah (2013) menjelaskan bahawa elong mempunyai corak tertentu, dilagukan dan mengandung makna. Untuk memahami makna elong, pengetahuan khusus diperlukan kerana elong mempunyai ciri-ciri 
tertentu sebagaimana halnya dengan sifat-sifat dalam puisi tetapi tidak mempunyai persamaan bunyi pada akhir setiap barisnya. Kemampuan untuk memahami makna elong sangat berkait dengan keupayaan melihat, mendengar dan merasakan imaginasi dan perasaan yang dilukiskan dalam elong.

\section{Metodologi}

Kajian ini merupakan kajian kualitatif, iaitu kajian lapangan, pemerhatian, temubual rawak dan analisis tekstual terhadap data dengan menggunakan pendekatan hermeneutik Paul Ricoeur. Informan yang dipilih terdiri daripada mereka yang melebihi usia 50 tahun dan arif dalam elong masyarakat Bugis di daerah Tawau. Informan yang berumur lebih 50 tahun tersebut dipilih kerana mereka masih berpegang teguh dan mengamalkan adat resam masyarakat Bugis di daerah Tawau.

\section{Kerangka Teori}

Pendekatan hermeneutik Paul Ricoeur telah digunakan untuk menganalisis data yang telah dikutip. Pendekatan hermeneutik yang diilhamkan Paul Ricoeur ini menggabungkan tradisi metodologi dengan tradisi falsafah. Falsafah menurut Rukayah dan Aziz (2018) ialah hermeneutik yang merupakan pengertian makna tersembunyi dalam teks yang terkandung makna untuk ditafsirkan secara berterusan.

Berkaitan dengan hermeneutik Paul Ricoeur, Acep (2008) telah menjelaskan bahawa Ricoeur menawarkan empat metodologi untuk mencapai objektiviti dan mengelakkan tafsiran yang subjektif, dengan menggariskan objektif melalui struktur, penyingkiran melalui tulisan, penyingkiran melalui teks dan peruntukan (pemahaman diri) yang memperlihatkan analisis struktural untuk menghuraikan atau mentafsir objek sehingga memungkinkan penafsiran menjadi lebih luas dan tepat (Ricoeur, 2006). Pendekatan Hermeneutik Paul Ricoeur adalah untuk mentafsir, menterjemah dan menyatakan serta menyingkap makna dalam teks. Setiap teks adalah berbeza dari sudut komponen dan struktur semantiknya. Oleh itu, untuk memahami teks memerlukan proses hermeneutik yang berbeza, iaitu kemampuan membezakan antara bahasa simbolik dan kiasan dibandingkan dengan bahasa yang tidak simbolik.

Manusia berkomunikasi menggunakan bahasa yang merupakan simbol dalam bentuk perkataan. Setiap kata tidak semestinya membawa makna secara langsung kepada penutur mahupun kepada pendengarnya (Mahfirotin Amalia, 2014). Dalam konteks ini, hubungan antara bahasa dengan hermeneutik saling bergantung antara satu sama lain. Bahasa sebagai simbol dan hermeneutik sebagai medium pentafsiran. Setiap bahasa mempunyai makna yang tersendiri dan bersifat multimakna. Peranan hermeneutik untuk menginterpretasi makna dari simbol-simbol bahasa yang dilontarkan sehingga maknanya dapat ditafsir secara jitu tanpa menimbulkan makna yang berlapis. Dalam erti kata lain, simbol-simbol tersebut bermula daripada subjektif kepada objektif. Dalam konteks ini, Paul Ricoeur berpendapat bahawa pandangan strukturalisme terhadap hermeneutik seperti ini tidak adil kepada bahasa. Oleh itu, Paul Ricoeur telah memperkenalkan hermeneutik teks tanpa menggunakan bahasa sebagai simbol-simbol untuk memberi makna. Sebaliknya, teks adalah simbol-simbol yang berdiri sendiri dan interpretasi makna diberikan tanpa terikat dengan penulis ataupun pengarang. 


\title{
Dapatan dan Perbincangan Kajian
}

Elong ialah aset kesusasteraan masyarakat Bugis berbentuk puisi yang kaya dengan khazanah budaya. Oleh itu, elong Bugis sangat penting untuk dikaji dan disebarluaskan agar dikenali oleh generasi muda, khususnya remaja Bugis yang terdapat di daerah Tawau, Sabah. Pada masa yang sama, belum terdapat kajian yang merungkai nilai siri' dalam elong Bugis di Sabah amnya dan di Tawau khasnya. Terdapat sembilan elong Bugis yang telah dianalisis secara berasingan kerana setiap elong Bugis mempunyai makna dan fungsi yang tersendiri.

\author{
Aja lalo masiri' makkutana, \\ massappa deceng, \\ ko loko maruntui dalle e'. \\ (Jangan malu bertanya, \\ mencari rezeki \\ kalau mahu berjaya). \\ (Mohd Basran Kapitan, 61)
}

Elong ini memberi suatu maksud tertentu selari dengan pandangan Ricoeur yang dipetik oleh Finah (2012) dalam Sumaryono (1999) yang mengatakan bahawa kata-kata adalah simbol yang menggambarkan makna lain yang berupa kiasan dan hanya difahami melalui simbolsimbol tersebut. Kebudayaan sentiasa tercermin daripada bahasa simbolik yang digunakan dalam berkomunikasi. Menurut Ricoeur, manusia berkomunikasi menggunakan bahasa kerana bahasa itu pada dasarnya ialah manusia dan ia merupakan syarat utama sebagai pengalaman manusia (Sumaryono, 1999).

Oleh itu, elong ini dilihat sebagai satu bahasa simbolik yang perlu ditafsir, diterjemah, dan didalami maknanya dalam teks. Elong tersebut menyatakan bahawa manusia dilahirkan dalam keadaan naif dan dianjurkan untuk rajin bertanya. Islam sendiri menganjurkan umatnya selalu bertanya seperti firman Allah yang bermaksud 'maka bertanyalah kepada orang yang mempunyai pengetahuan jika kalian tidak mengetahui' (an-Nahl: 43). Masyarakat Bugis sentiasa mengingatkan kepada anak-anak, saudara, dan sahabat-handai agar tidak malu untuk bertanya berkaitan urusan dunia atau urusan akhirat. Bertanya tidak menunjukkan kebodohan sebaliknya ia adalah kemuliaan dan tanda kerendahan hati seperti pepatah Melayu mengatakan 'malu bertanya sesat jalan' seperti yang dinayatakan oleh informan Mohd Basran (61), iaitu Aja lalo masiri makkutana (Jangan malu bertanya). Dalam mencari rezeki, masyarakat Bugis perlu sentiasa meneroka potensi diri untuk pergi lebih jauh seperti yang dinyatakan oleh informan Mohd Basran (61), iaitu massappa deceng, ko loko maruntui dalle e, yang bermaksud usaha untuk mencari rezeki boleh diperolehi melalui pekerjaan atau perniagaan. Dalam surah An Najm, ayat 39, Allah telah berfirman yang bermaksud 'dan bahawasanya seorang manusia tiada memperoleh selain apa yang telah diusahakannya.' 
Itai sige ananna tau e,

macca maneng,

demena gaga siri'di atimmu?

aja mappakkotu mbe,

finnajae alemu,

attunru-tunru ko musappai totomu,

ko loko madeceng.

(Lihatlah anak orang lain,

semuanya pandai,

tidak ada perasaan malu dalam hatimu?

jangan begitu nak,

sayangi dirimu,

berusahalah mencari nasibmu,

kalau kau mahu berjaya).

(Nadimah Mapiase, 58)

Elong tersebut mempunyai bahasa simbolik yang menunjukkan nasihat ibu bapa kepada anaknya yang masih menuntut ilmu. Menurut Ricoeur, setiap kata-kata merupakan simbol (Sumaryono, 1999) yang mengandungi makna tertentu dan memerlukan pentafsiran. Elong di atas bermaksud menuntut ilmu bukan sahaja menjamin pertambahan nilai dalam diri seseorang, tetapi mampu membentuk pemikiran yang sihat dalam membina masa depan yang lebih cemerlang. Kewajipan menuntut ilmu dalam pelbagai keadaan dan cara perlu dilakukan secara berterusan. Kefahaman tentang kepentingan ilmu dalam mencorakkan kehidupan pada masa akan datang memberi kesan langsung terhadap individu. Nilai-nilai positif seperti istiqamah, kuat semangat, sabar dan tidak mudah putus asa dalam menghadapi cabaran hidup juga digariskan. Oleh itu, ibu bapa dalam masyarakat Bugis sering membandingkan anak orang lain yang lebih bijak dalam menuntut ilmu agar tidak berasa malu pada kemudian hari. Perbandingan ini bukan untuk melemahkan semangat mereka, tetapi sebagai pemangkin semangat supaya mereka terus menuntut ilmu. Menurut informan Nadimah (58), iaitu ananna tau e, macca maneng dan demena gaga siri' di atimmu, dan madeceng merupakan simbol yang mempunyai makna seperti yang telah dijelaskan oleh Ricoeur (2006) dan M. Sastraprateldja (2013) yang menyatakan bahawa hasil yang diperoleh akan mendapat kesejahteraan dan kedudukan dalam masyarakat.

$$
\begin{aligned}
& \text { Padecengi gau mu, } \\
& \text { atutui kedo-kedomu, } \\
& \text { peliharai matammu, } \\
& \text { jagai timummu, } \\
& \text { cenning-cenningngi atimmu, }
\end{aligned}
$$

fanttujui nawa-nawammu. 
(Pelihara kelakuanmu,

jaga tingkah lakumu

jaga penglihatanmu

jaga tutur katamu

ikhlaskan hatimu

luruskan jalan fikiranmu).

\section{(Darming Nyompa, 50)}

Menurut pendekatan hermeneutik (Ricoeur, 2006), teks dilihat sebagai pautan antara bahasa isyarat dan simbolik, iaitu teks sebagai wacana yang disampaikan melalui tulisan untuk membatasi skop hermeneutik Paul Ricoeur melalui tafsiran teks sahaja. Ricoeur dalam Sumaryono, (1999), mengatakan bahawa kata-kata mengandungi makna untuk menerangkan sesuatu yang tersembunyi. Oleh itu, teks memerlukan pengamatan dan penyingkiran untuk menganalisis serta menghurai objek secara meluas dan tepat (Ricouer, 2006).

Jika elong di atas diamati dengan mendalam, setiap baris menyatakan erti yang khusus. Makna elong ini dapat ditafsirkan dengan mengetahui fikiran, dan perasaan orang yang mengucapkannya. Maknanya juga merujuk kepada cara tingkah laku dan memberi nasihat agar sentiasa menjaga perilaku bagi mengelak timbul salah sangka yang boleh mendatangkan permusuhan dalam kalangan masyarakat. Daripada penjelasan ini, dapat dikatakan bahawa masyarakat Bugis sangat menggalakkan komunikasi dalam kelompok mereka. Pengajaran yang boleh diperoleh daripada elong ini ialah berhati-hati selalu dalam menjalani kehidupan agar tidak menyinggung atau menyentuh sensitiviti orang lain. Subri (2016) menyatakan bahawa salah satu makna yang terkandung dalam konsep siri' ialah motivasi atau dorongan untuk melakukan sesuatu yang baik agar martabat dan kehormatan diri tetap terjaga.

Elong tersebut memperlihatkan simbolisme impian dalam masyarakat Bugis yang kaya dengan imej dan emosi. Meskipun imej yang disampaikan berbeza kerana perbezaan budaya, namun makna simbolik yang disampaikan bertujuan untuk memberi nasihat, bimbingan dan pengajaran kepada seseorang.

Narekko kado muaseng passelle watakkale muala passampo siri',

ikona tau masessa nataro siri mu,

nasaba sitongenna parobbiku,

watakkaleta tu kutajeng tannia kadota urennuang.

(Seandainya hadiah sebagai pengganti dirimu yang kau jadikan penutup malu engkaulah manusia yang terseksa dek kerana malumu, 
kerana sebenarnya undanganku, menantimu hadir di sisiku, bukan hadiah yang aku harapkan).

(Abdullah, 53)

Elong di atas mempunyai makna yang berlapis. Makna yang berlapis ini merupakan bahasa simbolik yang perlu dianalisis secara struktural untuk menghuraikan makna yang terdapat dalam teks. Oleh itu, untuk menghuraikan makna memerlukan pemahaman terhadap teks untuk menterjemah makna yang tersembunyi seperti. Menurut Ricoeur (2003), bahasa sinonim dengan pemikiran untuk mentafsir dan memberi makna. Elong ini memperlihatkan bahasa simbolik tentang maruah dan imej seseorang. Bahasa simbolik dalam elong ini memperlihatkan ketinggian budi bahasa masyarakat Bugis yang tidak dapat dinilai melalui kebendaan sebagai satu medium penyelesaian masalah, sebaliknya melihat keprihatinan dan ketulusan hati seseorang untuk meminta maaf.

Selain itu, elong ini juga memperlihatkan bahawa malu ialah perasaan negatif yang timbul dalam diri seseorang akibat perlakuan tidak senonoh yang dilakukan. Setiap orang yang normal mempunyai perasaan malu. Ahli dalam masyarakat mempunyai tanggapan yang berbeza mengenai malu, iaitu dari sudut pengertian malu, perkara yang mendatangkan malu serta tindakan yang harus dilakukan untuk mengatasi perasaan malu. Dalam masyarakat Bugis, malu atau disebut siri' merupakan satu perbuatan yang dianggap tabu. Perasaan malu sangat berkait dengan harga diri masyarakat Bugis. Kebiasaannya, orang yang melakukan kesalahan akan memohon maaf dan orang yang tidak bersalah akan memaafkan.

Dalam konteks elong yang berbunyi Narekko kado muaseng passelle watakkale muala passampo siri', ikona tau masessa nataro siri mu, nasaba sitongenna parobbiku, watakkaleta tu kutajeng tannia kadota urennuang (Abdullah, 53), masyarakat Bugis berpandangan bahawa memberi hadiah untuk menutup malu kepada orang yang dimalukan tidak akan mendatangkan penyelesaian. Perbuatan tersebut menambahkan lagi masalah kepada kedua-dua pihak. Pelaku seharusnya meminta maaf atas kesilapan memalukan orang lain. Permohonan maaf hendaklah dilakukan dengan tulus bagi memperbaiki perhubungan. Sebagai manusia, rasa sakit hati kerana dimalukan atau dianiayai bukanlah suatu perkara mudah dilupakan. Bagi mengekalkan keharmonian kedua-dua pihak seharusnya bersemuka untuk saling bermaafan dan menyelesaikan masalah. Cara ini dianggap sesuai mengikut budaya masyarakat Bugis.

Atutui siri'mu,

fa ianatu dionroang dilino e',

narekko tabbe siri'mu,

dena gaga tu manroang dilino e',

malebbi mokko mate'

e ISSN 2735 - 1904

https://doi.org/10.22452/JOMAS.vol32no1.3 
fa detona gaga sirimu,

fa kotuoko fappadako tu olokolo'e.

(Jaga malumu,

kerana malu kita hidup di dunia,

kalau hilang malumu,

tiada sudah yang dijaga di dunia ini,

lebih baik mati,

kerana sudah tidak ada malumu,

hidup pun seperti binatang)

(Niti, 60)

Ricoeur (2003) menjelaskan bahawa untuk menghayati simbol-simbol yang terdapat dalam teks, kefahaman terhadap simbol-simbol tersebut perlulah jelas. Kefahaman terhadap pesanan yang terdapat dalam teks, pemberian makna, dan penyampaian mesej perlu dilakukan agar dapat difahami oleh penerima. Simbol-simbol tersebut ditafsirkan semula untuk mendapatkan makna baharu bagi mengelakkan penyempitan makna. Sehubungan itu, elong yang diberikan oleh informan Puan Niti (60) mempunyai mekanisme dan struktur siri' yang diseragamkan dalam sistem organisasi sosial. Dalam masyarakat Bugis, siri' ialah perasaan malu dan harga diri yang menjadi nadi hidup manusia. Mereka yang kehilangan siri' dianggap sebagai orang yang tidak berguna dan lebih baik mati daripada hidup (malebbi mokko mate, fa detona gaga sirimu). Situasi ini bermakna masyarakat Bugis wajib menjaga siri'nya kerana merupakan syarat untuk meneruskan kehidupan di dunia ini (Farinnajai siri'mu, Faiatu dionroang dilino e). Adat yang disebut pangngadereng ini mengandungi siri' menjadi sumber rujukan dalam kehidupan masyarakat Bugis. Jika seseorang melanggar adat akan menjatuhkan siri", kehilangan siri' akan dikenakan kutukan sosial ( $F a$ kotuoko fappadako tu olokolo 'e) dan hukuman yang boleh membawa kepada hukuman mati seperti melarikan anak dara orang (silariang) atau didenda tanpa mengira pangkat dan darjat. Menurut Subri (2016), pelanggaran adat dalam masyarakat Bugis dianggap sebagai manusia yang sudah tidak memiliki siri' lagi.

Ade' merupakan salah satu elemen yang terkandung dalam pangngadereng. Ade' tidak mengenal sesiapa dan kedudukan seseorang. Hal ini dijelaskan dalam elong yang telah diberikan oleh informan Zahari (53) seperti berikut:

Ade'e degaga ananna, dettogaga oppona. 
(Adat tidak mempunyai anak, tidak juga mempunyai cucu)

(Zahari, 53)

Menurut Ricoeur, untuk memahami dan mentafsir sesebuah teks maka perlulah membuka ikatan simbol-simbol yang terdapat dalam teks terlebih dahulu. Dengan membuka makna yang tersembunyi secara simbolik akan mendapatkan makna lain menurut pandangan pembaca teks. Simbol yang terdapat dalam bahasa mempunyai banyak makna yang ada kalanya berupa bahasa kiasan untuk membongkar makna yang terkandung dalam teks tersebut. Oleh itu, dengan mentafsir makna elong di atas, secara harfiahnya dapat difahami bahawa adat tidak mempunyai anak dan tidak juga mempunyai cucu. Apabila simbol-simbol ini dihayati, elong di atas mempunyai maksud yang sangat luas. Elong tersebut merujuk kepada sistem keadilan dalam masyarakat Bugis. Keadilan yang dimaksudkan ialah pemberian sesuatu hukuman hendaklah adil (malempu) dan saksama serta tidak membelakangkan pangngadereng. Setiap hukuman yang dijatuhkan tidak melihat kedudukan, keturunan, pangkat dan darjat seseorang termasuklah anak atau cucu sendiri.

Dari sudut lain, elong juga memperlihatkan masyarakat Bugis sangat menjunjung tinggi adat mereka sehingga melupakan status dalam menjatuhkan hukuman. Adat yang terkandung dalam pangngadereng merupakan kata-kata Tuhan menurut kepercayaan Bugis. Melanggar adat maksudnya sama dengan melanggar perintah Tuhan. Sesiapa yang menjatuhkan hukuman dengan cara tidak adil dianggap telah melanggar adat yang terdapat dalam pangngadereng. Perlanggaran pangngadereng akan mengakibatkan perkara-perkara aneh berlaku seperti bencana alam, tanaman tidak menjadi, musim kemarau yang berpanjangan, dan sebagainya sebagai peringatan Tuhan atas penyelewengan dalam ade’.

Pasrah kepada Allah bermaksud menerima semua kejadian yang berlaku dan mengganggapnya sebagai ketentuan olehNya. Makna pasrah kepada Allah tidak membawa maksud hanya duduk diam atau bermalas-malasan tetapi hendaklah tetap berusaha dan selebihnya diserahkan kepada Allah. Daeng Massa (56), telah memberikan sebuah elong yang berkaitan dengan kepasrahan dan usaha serta tidak bongkak seperti berikut:

Makkareso reolo, nappa marillao doang rifuang Allah Taala, aja fappada iti e',

matempo mabbicara, makkedai na arekka tenna arekka, luttuka baja, itai ampena unrengnge, makkedai ko narekka fuange, 
luttukah baja.

(Berusaha dahulu, kemudian berdoa kepada Allah Taala, jangan seperti itik, bercakap bongkak, dia berkata samada dibenarkan atau tidak, aku terbang esok, lihat sifat itik serati, ia berkata, kalau Tuhan izinkan, aku terbang esok).

(Daeng Massa, 56)

Bahasa simbolik yang terkandung dalam sesuatu teks berhubung kait dengan tafsiran teks tersebut. Bagi memahami elong di atas, perluasan makna dalam pengertian yang lebih luas perlu dilakukan untuk menghasilkan pentafsiran dan interpretasi yang baharu dengan mengungkap simbol-simbol yang melambangkan usaha, tawakal, dan sifat kepasrahan kepada Tuhan. Ricoeur dalam Josef (2003) mengatakan bahawa simbol dan interpretasi saling berkaitan bagi menghuraikan makna yang tersembunyi dari makna yang terlihat. Setelah melakukan interpretasi dan membuka bahasa simbolik yang terdapat dalam elong di atas, dapat dilihat bahawa masyarakat Bugis menekankan kepada seseorang supaya berusaha terlebih dahulu kemudian barulah berdoa supaya apa yang telah diusahakan berjaya. Elong ini juga mengingatkan bahawa manusia jangan bersikap seperti itik yang bongkak dan sombong. Itik bersikap takbur dan menentang qada dan qadar Allah dengan mengatakan jika Tuhan membenarkan ia terbang atau tidak, ia tetap akan terbang. Kesombongannya telah membawa padah apabila ia tidak dapat terbang keesokan harinya. Itik serati pula dapat terbang disebabkan kerendahan hatinya dengan mengatakan sekiranya Tuhan mengizinkan, ia akan terbang. Pengajarannya ialah jangan bersifat takbur dan sombong apatah lagi menentang qada dan qadar Allah.

Sebagai manusia, kita harus menyerahkan aturan hidup kepada Allah. Dengan cara ini kita akur, tunduk, dan redha terhadap semua ketentuan_Nya. elong di atas, mengingatkan kita supaya jangan lalai dengan perintah Allah. Setiap usaha yang dilakukan hanya akan memperkenankannya ialah Allah. Tidak semua yang diusahakan akan berhasil. Oleh itu, masyarakat Bugis sering memberi nasihat kepada anak-anak mereka supaya sentiasa bersyukur dan bersangka baik terhadap Allah.

Getteng pula bermaksud keteguhan. Sebagaimana yang dinyatakan oleh Sitti (2017), getteng ialah nilai seperti tidak memungkiri janji, tidak mengkhianati sumpah, tidak membatalkan keputusan dan menyelesaikan pekerjaan. Dalam konteks ini, terdapat elong yang berkaitan dengan getteng seperti yang diberikan oleh informan Rahman (51), iaitu: 
Ko lauko massompe,

aja mulisu ko de muruntu i'totomu,

aja mengedda makkareso,

ko loko mitai decengmu.

(Kalau pergi merantau,

jangan kembali kalau tidak menemui apa yang kau cari,

jangan berhenti berusaha,

kalau mahu berjaya).

(Rahman, 51)

Kata-kata dalam elong di atas merupakan simbol perasaan dan harapan kepada seseorang yang pergi merantau. Dalam konteks ini, Ricoeur dalam Sumaryono (1999) mengatakan bahawa bahasa boleh dinyatakan dalam bentuk simbol yang membicarakan tentang sesuatu. Melalui teks elong di atas, seorang anak Bugis yang pergi merantau untuk mencari rezeki tidak digalakkan pulang jika masih belum mencapai cita-cita. Mereka haruslah sentiasa berusaha jika mahu berjaya dalam hidup. Dalam konteks ini, masyarakat Bugis sentiasa mengingatkan anak-anak mereka yang ingin keluar mencari rezeki di luar agar berusaha dengan bersungguh-sungguh sehingga mencapai kejayaan. Maksud jangan pulang kalau tidak berjaya hanya fiksyen yang berupa inspirasi kepada mereka. Perkara yang dipentingkan adalah jangan berhenti berusaha demi mencapai matlamat yang telah ditetapkan.

Selain itu, elong yang diberikan oleh informan Karim (53) pula adalah seperti berikut:

Ko taroko jangci,

akkatenningngi,

aja mobbokori,

fa tau e',

naita jangcimu.

(Kalau berjanji,

peganglah,

jangan membelakangkannya,

kerana orang,

melihat janjimu). 
Tafisran makna dan simbol-simbol yang terdapat dalam elong di atas adalah untuk mencari maksud yang bersesuaian dengan perkara yang ingin disampaikan. Sebagai manusia, kita tidak terlepas daripada berjanji, sama ada janji yang dilakukan sendiri atau dilakukan oleh orang lain. Dalam masyarakat Bugis, individu yang membuat janji perlu berpegang kepada janji yang telah dibuat oleh mereka. Janji tidak boleh dimungkiri, jika mahu dipercayai oleh orang lain. Individu yang memungkiri janji, sukar dipercayai oleh orang lain dan digambarkan dengan elong di atas.

Sipakatau bermaksud berbaik sangka kepada semua atau memanusiakan manusia. Dalam masyarakat Bugis sipakatau dianggap sebagai orang yang budiman. Dalam hal ini terdapat elong yang diberikan oleh informan Adam (50) seperti berikut:

Aja masekke membereang warang parang,

deto mutiwi lettu dikalobbongmu,

tuoki rilinoe,

aja mangingngi mammase-mase,

nafa iyanatu nafuji Fuangnge.

(Jangan kedekut memberi,

tidak juga kau bawa sampai ke liang lahat,

jangan malas berkasih sayang,

kerana itu yang Tuhan suka).

(Adam, 50)

Bahasa simbolik elong di atas menerangkan tentang sipakatau (memanusiakan), iaitu satu konsep yang berkait rapat dengan interaksi manusia dengan manusia yang lain. Melalui interaksi ini, masyarakat dapat mengeratkan hubungan silaturahim. Konsep sipakatau akan melahirkan hubungan positif melalui kasih sayang dan persaudaraan. Elong di atas memperlihatkan bahawa masyarakat Bugis menggalakkan supaya sentiasa memberi bantuan kepada sesiapa tanpa mengira agama, bangsa, dan pangkat. Harta kekayaan tidak akan dibawa sehingga ke liang lahat melainkan amal jariah sahaja. Oleh itu, masyarakat Bugis sangat menekankan sifat berkasih sayang kerana perbuatan seperti ini akan mendapat reda Sang Pencipta seperti yang digambarkan dalam elong di atas. Dengan erti kata lain, elong di atas memperlihatkan hubungan manusia dengan Tuhan dan hubungan manusia dengan manusia. Melalui konsep sipakatau masyarakat Bugis dapat mengukuhkan hubungan persaudaraan.

Selanjutnya elong berikut yang diberikan oleh Massarapi (56) berbunyi seperti berikut:

Namo faddissengengmu matanre mallongi-longi,

kodegaga sifa-sifa sippakatau diatimmu, 
degaga guna-gunana,

ikona tu tau fappada olokkoloe.

(Biarpun ilmumu setinggi langit,

kalau tidak ada sifat-sifat manusia dalam hatimu,

tidak ada gunanya,

engkau adalah manusia seperti binatang).

(Massarapi, 56)

Menurut Ricoeur, kata-kata merupakan simbol yang terdapat dalam teks yang mengandung makna lebih dari satu. Dapatan kajian ini memperlihatkan bahawa elong memiliki simbol yang mempunyai makna besar. Elong tersebut menjelaskan bahawa manusia yang tidak mempunyai sifat sipakatau diupamakan seperti berhati binatang. Dalam konsep perkataan sipakatau, iaitu kasih sayang, masyarakat Bugis disifatkan tidak mempunyai perasaan. Jika nilai tersebut tidak dimiliki, meskipun mempunyai ilmu pengetahuan yang tinggi, manusia tersebut tidak berguna. Sipakatau juga dapat simbolik kepada perasaan belas kasih atau sifat ehsan. Masyarakat Bugis diwajibkan memiliki nilai tersebut bagi mengangkat nilai dirinya dalam masyarakat. Masyarakat Bugis sangat memberi penekanan kepada konsep saling menghormati, berbudi bahasa tanpa melihat suku bangsa. Oleh itu, tidak hairanlah jika masyarakat Bugis menanamkan sifat-sifat sipakatau sejak dari kecil lagi kepada anak-anak mereka. Dalam masyarakat Bugis, sifat manusiawi sangat ditekankan dalam konsep siri'yang menjadi tunggak maruah masyarakat Bugis.

Selain perkataan sipakatau, masyarakat Bugis juga memiliki lempu, iaitu merujuk kepada hubungan interpersonal. Hubungan ini meliputi kepatuhan kepada Tuhan, kepercayaan, menghormati hak orang lain, kerendahan hati, dan sukarela menolong orang lain tanpa meminta balasan (Sitti, 2017). Elong di bawah telah diberikan oleh informan Yakin (89) yang berbunyi seperti berikut:

Gauk magollo,

iyanatu tiwiko matu,

lao rimadecengnge.

(Sifat terpuji,

(itu yang akan membawamu nanti, kepada kebaikan).

(Yakin, 89) 
Untuk mencari maksud elong tersebut, pengkaji melihat metafora dan simbol yang terdapat dalam teks dengan menggunakan penjarakan tulisan yang diperkenalkan oleh Paul Ricoeur untuk mentafsir makna yang terdapat dalam teks supaya persoalan akan menjadi jelas. Teks tidak semestinya bersifat otonom tetapi berkaitan dengan konteks yang terdiri daripada pelbagai aspek. Oleh itu, teks elong memperlihatkan bahawa manusia akan mendapat kejayaan jika mempunyai sifat-sifat terpuji. Oleh itu, elong tersebut mengingatkan bahawa sifat terpuji merupakan salah satu syarat untuk mencapai kejayaan dan dihormati oleh ramai orang. Terdapat banyak sifat-sifat terpuji, seperti taat dalam beribadat, menghormati orang lain, kerendahan hati, menolong sesama manusia tanpa mengharapkan balasan, dan sebagainya.

Masyarakat Bugis sentiasa mengingatkan anak-anak mereka supaya selalu bercakap benar. Hal ini jelas dinyatakan oleh elong yang diberikan oleh informan Abdullah (50) seperti berikut:

\author{
Aja lalo mebbelle-belle, \\ rifadatta rupa tau, \\ syisyeng ko mabbelle, \\ tabbe tongenni tu siri'mu, \\ nafa denagaga tu mpuji, \\ sifa-sifa aтрепи. \\ (Jangan menipu, \\ sesama manusia, \\ sekali menipu, \\ hilang rasa malumu, \\ kerana tiada yang menyukai, \\ sifat-sifatmu).
}

(Abdullah, 50)

Perkara yang berlawanan dengan sifat terpuji ialah sifat buruk yang perlu dihindari. Menerusi elong tersebut, sifat terpuji dalam masyarakat Bugis ialah bersifat jujur dan ditegah melakukan penipuan kerana perbuatan tersebut akan merendahkan nilai diri. Elong di atas mempengaruhi pola kemunikasi masyarakat Bugis secara vertikal mahupun horizontal dalam hidup bermasyarakat. Simbol-simbol yang ditonjolkan dalam elong tersebut dianggap sebagai salah satu realiti sosial yang berlaku dalam masyarakat Bugis selaras dengan pandangan Ricoeur. Menurutnya, simbol ialah kata kerana setiap perkataan pada dasarnya bersifat konvensional dan tidak membawa maknanya secara langsung kepada pembaca atau pendengar. Tafsiran elong di atas dari sudut pandangan Ricoeur adalah sebagai kehidupan masyarakat Bugis yang dituntut untuk sentiasa berkata benar. Aja lalo mebbelle-belle, rifadatta rupa tau, membawa maksud jangan 
sesekali menipu orang lain. Hal ini demikian kerana menipu ialah perbuatan yang tidak disukai oleh semua orang. Penipuan yang dimaksudkan disini meliputi beberapa perkara seperti menipu dalam perniagaan, menipu kerana mahu menutupi kesalahan yang telah dilakukan, menipu kerana takut diasingkan, dan sebagainya.

Rapang merupakan salah satu daripada inti pangngadereng. Dari sudut bahasa rapang ialah contoh, misal, ibarat, atau perumpamaan, persamaan atau kias (Mattulada, 1985). Rapang mempunyai ruang lingkup yang sangat luas. Fungsi rapang seperti yang dinyatakan dalam Latoa (1985) yang bermaksud undang-undang, perbandingan, alat pelindung, iaitu melindungi hak umum dan melindungi seseorang dari bahaya dan pemmali. Dengan kata lain, rapang bersifat multifungsi dalam memberi penjelasan perkara-perkara yang boleh dan tidak boleh dilakukan oleh masyarakat Bugis.

Menurut informan Rahman (55), rapang ialah peringatan atau sebagai paseng untuk melakukan perkara yang dibenarkan dan tidak dibenarkan seperti elong yang diberikannya di bawah ini:

\author{
Aja massering, \\ aja mabbissa penne, \\ aja mukala-lau, \\ di wenninna juma'e \\ pemmalinna tao rioloe. \\ (jangan menyapu, \\ jangan mencuci piring, \\ jangan ke mana-mana, \\ pada malam Jumaat, \\ pantang larang orang dahulu).
}

Rahman (55)

Dalam konteks elong di atas, larangan merupakan simbolisme hubungan antara manusia dengan Tuhan. Elong ini memperlihatkan sistem nilai masyarakat Bugis yang mengajar generasi mereka supaya mengenal Tuhan. Dengan menggunakan elong sebagai perantara komunikasi dalam masyarakat yang didasari oleh sosiologi pemikiran mereka, elong tersebut merupakan larangan melakukan perkara pada malam hari Jumaat. Larangan tersebut bukanlah bersifat mutlak. Setelah berlaku proses Islamisasi di Sulawesi, kebanyakan masyarakat Bugis menerima Islam. Pengislaman masyarakat Bugis menyebabkan proses sosialisasi masyarakat Bugis, terutamanya yang menyentuh tentang ketuhanan. Amalan-amalan semasa pra-Islam telah digantikan dengan konsep tauhid dan fiqh menurut syariat Islam yang disebut sebagai sara' yang telah disusup masuk 
ke dalam pangngadereng. Oleh itu, timbullah larangan melakukan sesuatu pada malam hari Jumaat. Tujuannya ialah untuk memudahkan mereka mendalami ajaran Islam dengan mengadakan bacaan al-Quran atau mendengar tazkirah daripada guru-guru agama pada malam Jumaat. Hari Jumaat merupakan hari yang mulia dan penghulu segala hari menurut pandangan Islam. Gambaran elong di sini bersifat umum kepada semua orang Bugis yang mengamalkan budaya dan tradisi mereka setelah kedatangan Islam.

Manusia hendaklah sentiasa bersyukur dan bersujud kepada Tuhan Yang Maha Kuasa kerana setiap rezeki yang diperolehi adalah kurniaan-Nya. Masyarakat Bugis melarang anak-anak mereka daripada melakukan sesuatu yang membelakangi Tuhan dari setiap sudut. Hal ini jelas dinyatakan dalam elong yang diberikan oleh informan Brahim (50) seperti berikut:

Namo aga jamannu,

nakko de musuju'

rifuangnge,

demullei mitai decengnge’.

(Apapun pekerjaanmu,

tapi kalau tidak bersujud,

kepada Tuhan,

engkau tidak akan melihat kebaikan).

(Brahim, 50)

Dalam elong ini digambarkan terdapat hubungan antara manusia dengan Tuhan. Simbolsimbol yang terdapat elong ini jelas menggambarkan peringatan kepada seseorang yang menjadi sebahagian daripada struktur sosial dalam hidup beragama dan bermasyarakat. Elong di atas menunjukkan bahawa masyarakat Bugis menekankan ketaatan kepada Yang Maha Kuasa. Manusia sentiasa bergantung kepada Tuhan. Oleh itu, kejayaan yang dikecapi tidak bermakna jika tidak bersyukur kepada Tuhan dan hati akan sentiasa berada dalam keadaan resah gelisah. Setiap individu dalam masyarakat Bugis sentiasa diingatkan bahawa hendaklah sentiasa bersyukur untuk mendapatkan ketenangan jiwa. Dalam konteks ini, manusia yang diciptakan oleh Allah hendaklah mempunyai rasa malu (siri') terhadap Tuhannya dengan menyukuri nikmat dan bersujud kepada Tuhan.

\section{Kesimpulan}

Elong Bugis bukan sahaja menjadi hiburan, tetapi berfungsi sebagai medium perhubungan untuk menyatakan fikiran dan perasaan bagi masyarakat Bugis khasnya di Daerah Tawau, Sabah. Nilainilai siri' dalam elong merupakan gagasan tentang harga diri dan kehormatan keluarga. Ekspresi 
yang dinyatakan dalam elong juga menggambarkan kepentingan menjaga kelakuan agar tidak melanggar adat dan budaya siri'yang disanjung oleh masyarakat Bugis. Dari sisi lain, elong masih lagi menjadi wadah untuk menyampaikan pappaseng (pesan) untuk generasi Bugis pada masa akan datang.

\section{Rujukan}

Abdul Asis. (2010). Refleksi nilai religius dalam Elong Ugi To Panrita (Reflection of religious value in The Poem of Prayist). Jurnal "Al-Qalam", Vol. 16, No. 25, 51-62.

Abdullah Muhammad Ali. (2009). Kelong dalam perspektif Hermeneutika. Disertasi. Program Studi Pendidikan Bahasa Indonesia. Program Pascasarjana. Universitas Negeri, Malang, Indonesia.

Acep Iwan Saidi. (2008). Hermeneutika, sebuah cara untuk memahami teks. Jurnal Sosioteknologi, Edisi 13, Tahun 7, 376-382.

Andi Wahyani Afifa Syarif. (2018). Penguasaan makna Elong Ala Masea Sea Siswa Kelas VIIISMP Negeri 25 Cenrana Kabupaten Maros. Skripsi. Fakultas Bahasa dan Sastra, Universitas Negeri, Makassar, Indonesia.

Asmiaty Amat Amat (peny.). (2012). Siri etnik Sabah: Bugis Sabah. Kuala Lumpur: Institut Terjemahan dan Buku Negara.

Asmiaty Amat Amat. (2012). Syair Bugis dan pengekalan siri dalam adat perkahwinan Bugis. Jurnal Pengajian Melayu/Journal of Malay Studies (JOMAS). Akademi Pengajian Melayu, Universiti Malaya. Vol. 23. No 1, 66-83. Retrieved from https://ejournal.um.edu.my/index. php/JPM/article/view/25678.

Finah Septiani. (2012). Konsep religiusitas pada puisi-puisi karya Teguh Trianton tahun. 20032009 (Kajian Simbol Hermeneutika Paul Ricoeur). Pendidikan Bahasa dan Sastra Indonesia. Universitas Muhammadiyah Purwokerto, Surakarta, Indonesia.

Halijah. (2016). Nilai-nilai pendidikan dalam Elong Ugi Toto naskah transliterasi dan terjemahan Muhammad Salim. Tesis. FBS. Universitas Negeri, Makassar.

Herianah. (2013). Variasi bentuk reduplikasi dalam lirik lagu Bugis: Kajian stilistika. Sawerigading. Vol. 19, 17-25.

. (2011). Analisis wacana dalam Elong Ugi To Panrita: Aspek kohesi dang ra ma tikal (Discourse analysis in Elong Ugi to Panrita: Cohesion and grammatical aspect). Sawerigading, Vol. 17, No. 1, 147-156.

. (2009). Gaya bahasa dalam Elong Ugi Pammulang Elong (Stylistic analysis of Elong Ugi Pammulang Elong). Sawerigading, Vol. 15, No. 3, 361-371.

Imami Nur Rachmawati. (2007). Pengumpulan data dalam penelitian kualitatif: Waw ancara. Jurnal Keperawatan Indonesia, Vol. 11, No. 1, 35-40.

Iskandar. (2016). Bentuk, makna, dan fungsi Pappaseng dalam kehidupan masyarakat $\quad \mathrm{B} \mathrm{u} \mathrm{gis}$ di Kabupaten Bombana. Jurnal Bastra Vol. 1, No. 2.

Ismail Suardi Wekke. (2013). Islam dan adat: Tinjauan akulturasi budaya dan agama dalam 
masyarakat Bugis. Analisis, Vol. XIII, No. 1, 27-56.

Johar Amir \& Ambo Dalle. (2010). Pappaseng Alempureng sebagai sarana diri pada masyarakat Bugis. Makassar, Indonesia: Universitas Negeri.

pengendalian

Mahfirotin Amalia. (2014). Hermeneutika III Pemikiran Paul Riceour dan Jacques Derrida. Tesis. IAIN Sunan Ampel, Surabaya, Indonesia.

Mahluddin. (2017). Telaah kritis nilai edukatif pappaseng dalam Elong Ugi. Tesis. Universitas Muhammadiyah, Makassar, Indonesia

Mattulada. (1985). Satu lukisan analitis terhadap antropologi politik orang Bugis. Jakarta, Indonesia: Gadjah Madah University Press.

Mustafa. (2011). Imajinasi dalam penciptaan Elong. Metasastra, Vol. 4. No 1, 45-54.

Nensilianti dalam Nurfathana. (2013). Analisis stilistika dan nilai-nilai moral Nyanyian Rakyat Bugis Kumpulan Teks Elong Ugi serta implikasi terhadap perangkat pembelajaran sastra di SMPN 2 Sinjai. Universitas Pendidikan, Indonesia.

Nurul Rabianti. (2018). Cenningrara' mantra pakasi’ di Kabupaten Soppeng (Kajian Semiotik Rifaterre). Tesis. Universitas Negeri, Makasar, Indonesia.

Ricoeur, Paul. (2006). Hermeneutika ilmu sosial. Terjemahan oleh Muhammad Syukri. Yokyakarta, Indonesia: Kreasi Wacana.

. (2003). Filsafat wacana, membelah makna dalam anatomi bahasa. Terj. Musnur Hery. Yogyakarta, Indonesia: Ircisod.

(2003). In Josef Bleicher, Hermeneutika Kontemporer. Terj. Ahmad Norma Permata. Yogyakarta, Indonesia: Fajar Pustaka.

Rukayah \& Aziz Thaba. (2018). Modus ekspresi kearifan lokal masyarakat Bugis: Suatu kajian elong ugi dengan perspektif Hermeneutika. Metalingua, Vol. 16, No. 2, 257-272.

Sikki \& Nurwahyuni (2018). In Andi Wahyani Afifa Syarif. Penguasaan makna Elong Ala Masea Sea Siswa Kelas VIII SMP Negeri 25 Cenrana Kabupaten Maros. Skripsi. Fakultas Bahasa dan Sastra, Universitas Negeri, Makassar.

Sitti Rahmi, Andi Mappiare-AT \& Muslihati. (2017). Karakter ideal konselor dalam budaya Bugis kajian Hermeneutik terhadap teks Pappaseng. Jurnal Pendidikan, Vol. 2, No. 2, pp. 228237.

Subri dan Mahsyar Idris. (2016). Kajian Rekonstruksi Budaya Siri Bugis Ditinjau dari Pendidikan Islam (the "Study Reconstruction Culture Siri" "Bugis Seen From Islamic Education). Istiqra’ Vol. IV No. 1, 8-24.

. (2016). Kajian rekonstruksi budaya Siri Bugis Ditinjau dari pendidikan Islam. Jurnal Studi Pendidikan, Vol. XIV (No. 2), 155-177.

Sudarmin Harun. (2014). Explicit and implicit meanings in Elong Buang Tassanra Mua. Jurnal Ilmu Budaya. Vol. 2, No. 1, 281-292.

Sumaryono dalam Rukayah dan Aziz Thaba. (2018). Modus ekspresi kearifan lokal masyarakat Bugis: Suatu kajian Elong Ugi dengan perspektif Hermeneutika. Metalingua, Vol. 16, No. 2, 257-272. 
.(1999). Hermeneutika: Sebuah metode filsafat. Yogyakarta, Indonesia: Kanisius.

Surah an-Nahl. (2009). Yaamil al-Quran the miracle. Bandung, Indonesia: PT Sygma Examedia Arkanleema.

Surah An Najm. (2009). Yaamil al-Quran the miracle. Bandung, Indonesia: PT Sygma Examedia Arkanleema.

M. Sastraprateldja. (2013). Hermeneutika dan Etika Naratif Menurut Paul Ricoeur. Kanz Philosophia A Journal for Islamic Philosophy and Mysticism, pp. 247-263.

Syamsurijal. (2017). Parupama: Nasehat yang menghibur. Jurnal Lektur Keagamaan, Vol. 15, No. 2, 295-317.

Uniawati. (2013). Simbol khusus dalam Elong Ugi Klasik (Private symbols in Classic Buginese Song). Kandai, Vol. 9, No. 1, 71-81.

\section{Informan}

Abdullah, (50 tahun), Table, (Tawau), Sabah pada 12 Februari 2020.

Abdullah Nase, (53 tahun), Tanjung Batu Laut, (Tawau), Sabah pada 17 Mac, 2020.

Adam Masiga (50 tahun), Taman Semarak, (Tawau), Sabah pada 2 Mac 2020.

Brahim Abdul (50 tahun), Semarak Megah (Tawau), Sabah pada 18 Mac 2020.

Daeng Massa, (56 tahun), Taman Ria, (Tawau), Sabah pada 6 Februari 2020.

Darming Nyompa, (50 tahun), Ranggu, (Tawau), Sabah pada 28 April, 2020.

Karim Palalloi (53 tahun), Bombalai, (Tawau), Sabah pada 7 Mac 2020.

Massarapi Kaile (56 tahun), Kongsi 10, (Tawau), Sabah pada 11 Disember 2019.

Mohd Basran Kapitan, (61 tahun), Kg. Pasir Putih, (Tawau), Sabah pada 12 Mac, 2020.

Nadimah Mapiase, (58 tahun), Kg. Pasir Putih, (Tawau), Sabah pada 3 Januari, 2020.

Niti Arsyad, (60 tahun), Kg. Titingan, (Tawau), Sabah pada 25 Mei, 2020.

Rahman Sahibe (55 tahun), Sin Onn, (Tawau), Sabah pada 2 Mac 2020.

Rahman Suali (51 tahun), Kg. Pasir Putih, (Tawau), Sabah pada 10 Januari 2020.

Yakin Massakirang, (89 tahun), Taman Ria, (Tawau), Sabah pada 20 Januari 2020.

Zahari Lorong, (53 tahun), Ranggu, (Tawau), Sabah pada 23 Februari 2020. 